\title{
Sport, Physical Recreation, and the National Health*
}

\author{
ROGER BANNISTER
}

British Medical fournal, 1972, 4, 711-715

It is perhaps fortunate that the opportunity to give this Chadwick lecture comes at a time when the Sports Council is for the first time launching a campaign to increase sports participation and improve facilities for sport and physical recreation in Britain. I believe that at the same time a rather cunning trap has been laid for me, and I want it known straight away that I have no intention of falling into it. The snare set for me consists, of course, in the temptation offered to me as a medical man and chairman of the Sports Council to declare that there is a strong, positive, and unambiguous relationship between sport and physical recreation on the one hand and health on the other, and to indicate that Sports Council policy is in some sense based on this relationship.

\section{Sport is its Own Justification}

The fundamental plinth on which our policy rests is the assumption that sport is a natural, worth while, and enjoyable form of human expression and eminently deserves support in its own right and for its own sake. I would not like to try to imagine a world in which there were no games to play, no chance to satisfy the natural human impulses to run, to jump, to throw, to swim, to dance. The Arts Council, the proponents of music, painting, and literature, do not seek to justify these things by pointing to some superior good. They regard music and painting as in themselves eminently worth while and desirable. And this, I suggest, is how we should look on physical recreation.

The historic Physical Training and Recreation Act 1937 originated from a British Medical Association report on the declining fitness of the population. As one reads the Commons' debate on this Bill it is like passing through a desert and suddenly stumbling on an oasis to come on Aneurin Bevan's blunt *Chadwick Trust Lecture delivered at Church House, Westminster, 26
September 1972 .

Sports Council, London W1N 4AJ

ROGER BANNISTER, C.B.E., D.M., F.R.C.P., Chairman and pithy answer to those whose support of the Bill was in terms of its beneficial side effects: ". . . the desire to play is a justification in itself for playing." "Compulsory enjoyment comes near to being a contradiction in terms," the Wolfenden report ${ }^{1}$ remarked. We do, however, want to inspire everyone to wish to take part by making the choice irresistible in its scope and variety. The whole focus of our policy is on providing opportunities for participation and, above all, opportunities for all.

\section{Modern Setting}

Many factors have led to the increasing demand for leisure:

Shorter Working Week.-In the U.K. the working week for male manual workers has (admittedly with some ups and downs) fallen gradually over the past two decades from $47 \cdot 8$ hours in 1951 to $44 \cdot 7$ hours in 1971 .

Longer Holidays. - The proportion of manual workers in the U.K. entitled to three weeks or more holiday with pay has soared dramatically from $1 \%$ in 1951 to $67 \%$ in 1971 . The vast majority of people still spend their holidays in Britain, not as some might believe on the Costa Brava.

TABLE I-Cost of Participation in Sport and Recreation (in shillings)

\begin{tabular}{|c|c|c|c|}
\hline \multicolumn{2}{|l|}{ Activity } & $\begin{array}{c}\text { Average Cost per } \\
\text { Participant Each Time } \\
\text { Took Part } \\
\text { (All Participants) }\end{array}$ & $\begin{array}{c}\text { Average Total Annual } \\
\text { Expenditure (Regular } \\
\text { Participants } \\
\text { Only) }\end{array}$ \\
\hline 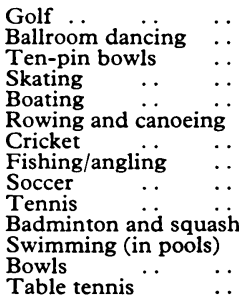 & $\begin{array}{l}\cdots \\
\cdots \\
\cdots \\
\cdots \\
\cdots \\
\cdots \\
\cdots \\
\cdots \\
\cdots \\
\cdots\end{array}$ & $\begin{array}{l}5 \cdot 4 \\
4 \cdot 5 \\
4 \cdot 1 \\
3 \cdot 8 \\
3 \cdot 6 \\
3 \cdot 4 \\
2 \cdot 2 \\
2 \cdot 1 \\
2 \cdot 1 \\
2 \cdot 0 \\
1 \cdot 8 \\
1 \cdot 3 \\
1 \cdot 2 \\
0 \cdot 9\end{array}$ & $\begin{array}{c}164 \cdot 0 \\
168 \cdot 1 \\
113 \cdot 3 \\
80 \cdot 9 \\
* \\
* \\
49 \cdot 0 \\
57 \cdot 3 \\
64 \cdot 6 \\
32 \cdot 3 \\
* \\
27 \cdot 3 \\
19 \cdot 2 \\
*\end{array}$ \\
\hline
\end{tabular}

* Number of players insufficient to furnish reliable average figure.

1 Shilling $=5$ p.
(From Government Social Survey, 1969, by Sillitoe, ${ }^{3}$ by kind permission.) 
Income.-Despite inflation there has been a continuing increase in real income for most sections of society (to be exact from 70.7 in 1951 to 115.4 in 1971 , taking 100 in 1963 as the base ${ }^{2}$ ). This means that more money is available for leisure Table I). ${ }^{3}$

Population.-The total population of the U.K. has risen by $10 \%$ over the past two decades-from 50.3 million in 1951 to 55.6 million in 1971. Within this global increase, however, the more "leisured" groups have increased their proportionate contribution-the school/college population by 100,000 from 1966 to 1970 and people over retirement age by 3.2 million during the two decades.

Car Ownership.- The number of private cars in Britain rose from 2.5 million in 1950 to 11 million in 1968 , and projections for the end of the century currently run at 28 million. Of course, growth in car ownership may mean less exercise, but it is an indicator of more wealth and makes leisure possibilities more flexible.

Industrialization.-This consists, essentially in the widespread application of mass production, which in turn makes for more and more routine tasks lacking in intrinsic interest and satisfaction.

Urbanization.-Eighty per cent of the U.K. population are now classified as urban. Together with the Netherlands this is the highest figure in Western Europe.

All this adds up to a wonderful opportunity for a new approach to active leisure. Instead of dolefully deploring the automated, push-button, car-driving age we live in should we not look at the whole picture in another light? We should be very grateful to have a population that is not exhausted by the demands of the working day and has energy and time left over at the end of it to be free to choose its leisure pursuits from a much wider range of activities than ever before.

\section{Possible Social Effects of Taking Part}

Within this pattern of increasing leisure consequences sometimes attributed to taking part in sport-for example, improved health, reduced delinquency rate-are to be counted as bonuses.

\section{LESS DELINQUENCY}

Is it possible that energetic, ebullient, even courageous youths need an outlet in risk-exposure sport beyond the streets and confines of their dwellings ? There is no convincing evidence of this relationship but our general feeling here is somewhat along the lines of Dr. Johnson's sentiment in noting that a man is never so harmlessly occupied as when making money. We could say that no one is ever so harmlessly occupied as when chipping out of a bunker or fielding at leg-slip or giving his all in the squash court.

\section{PSYCHOLOGICAL BENEFITS}

The Wolfenden report, ${ }^{1}$ which says so many wise things about sport so well, seems to hit the nail on the head when it comments: "It is not in actual fact obvious that those who have been brought up on competitive team games are more unselfish, co-operative and self-sacrificing than those who have not; and we should not wish to press this particular argument too far." In a society in which authority is supposedly increasingly defied and rules are broken it is the rules and internal discipline of sport that can be seen to have force. If you don't duck at the call "gybe oh" when sailing you may well be knocked overboard by the boom.

The strands of life and motive are not only woven but also tangled, and no amount of medical research will disentangle them all. But let us consider those vaguest and least measurable of social ills - anxiety, apathy, loneliness, boredom, and the kind of unease that directly or indirectly takes a third of patients to a doctor's door. You may know the story of the worried man who went to his doctor for help and was told to take up golf with the words: "If you play good golf it shows your mind is on it and if you play bad golf you'll think of nothing else." How many patients like this are making an appeal which in these sophisticated days cannot be satisfied by a bottle of medicine or by a course of psychotherapy? Sport cannot heal deep psychological wounds but we have yet to discover how far a pervasive indeterminate malaise might be assuaged for many people by some form of physical recreation.

\section{HEALTH}

The relation between sport and health is very complex because neither sport nor health are unitary concepts. There is evidence that over the past few decades a decline has taken place in certain physiological standards within advanced industrial societies of the Western world. McIntosh ${ }^{4}$ clearly outlined the evidence which led to the growth of this fear in the most industrially advanced of all the nations-America. (The most telling statistic here was that the rejection rate among army candidates was growing yearly and by 1959 was twice what it had been during the second world war: to recruit 196,000 men for the Berlin crisis it was necessary to call up about 750,000). Cardiovascular diseases are now accounting for more than half the deaths in this country, far more than cancer and infectious diseases combined, and the first pathological changes have been found in teenagers.

\section{Physical Effects}

Taking sport as it were on the left-hand side of the equation let us consider in turn different facets of health on the right-hand side of the equation.

\section{POSSIBLE DISADVANTAGES}

Geiringer ${ }^{3}$ recently put his finger on some dangers which are real and need to be publicized among doctors and physical education experts. The Sports Council has a research study on hand which is seeking, from the club and players' end, to gauge more accurately the extent of this problem and to suggest remedies for it. Another project now starting will among other things seek ways of improving the present uneven methods of casualty, orthopaedic, and physical medicine treatment. Incidentally, in connexion with research into possibly injurious effects of sport the Sports Council supported the Royal College of Physicians' study on professional boxing and are currently, with St. Thomas's Hospital, funding a project for the detection of anabolic steroids.

Improved treatment for sports injuries once they have occurred, however, is clearly only a partial answer. What is needed above all is a better system of prevention of these injuries. Pretraining exercises are often made a condition of acceptance on, for instance, courses in skiing (a condition which the Sports Council imposes) but in many other types of sporting activity hardly occur at all. There are enormous opportunitieswhich in the end probably fall largely to the medical professionfor reducing the incidence and seriousness of sports injuries by educating participants in appropriate prematch and preseason exercises.

\section{BENEFITS}

Fitness.-This is definable and measurable and something about which certain conclusions have already been drawn. ${ }^{6}$ Physical fitness can be taken to mean the capacity to enjoy 
moderate endurance activity appropriate to the person's age, such as walking, cycling, or jogging, without discomfort either during or after the exercise. The physiologist measures physical fitness by an improved capacity to perform such endurance exercise after training. It can be stated quite emphatically that all physiologist scientists agree that regular endurance activity, which approaches for a short time the maximum for that individual, results in increased physical fitness. This statement should be enough to commend physical activity to the inactive who wish to acquire fitness. I do not believe that there is an intellectually respectable argument against this point of view.

Health.-Leaving physical fitness we come into some really formidable problems in measurements of health. Certainly the W.H.O. definition-“"a sense of social, physical and mental well being"-cannot be used for research purposes.

Reduced Cardiovascular Mortality and Morbidity.-Investigators are in practice forced back on to the cold tests of mortality and morbidity and left to seek associations between lack of exercise and morbid changes of certain types, usually in the cardiovascular field. Pincherle ${ }^{7}$ among others has shown that inactive people have higher cholesterol levels (Table II). There are

TABLE II-Effect of Exercise on Mean Cholesterol (mg/100 ml) Values in Different Age Groups Based on Examining Doctor's Opinion of Amount of Exercise Taken by Patient

\begin{tabular}{|c|c|c|c|c|}
\hline \multirow{2}{*}{\multicolumn{2}{|c|}{ Age (Years) }} & \multicolumn{2}{|c|}{ Amount of Exercise } & \multirow{2}{*}{$t$ Test } \\
\hline & & Inadequate & Adequate & \\
\hline $\begin{array}{ll}25-34 & \ldots \\
35-44 & \ldots \\
45-54 & \ldots \\
55-64 & \ldots \\
\end{array}$ & $\begin{array}{l}\ldots \\
\cdots \\
\cdots\end{array}$ & $\begin{array}{l}246 \quad(334) \\
255(1,135) \\
263(1,073) \\
260(584)\end{array}$ & $\begin{array}{ll}237 & (399) \\
251 & (1,307) \\
259 & (1,351) \\
262 & (763) \\
\end{array}$ & $\begin{array}{l}\mathbf{P}<0.01 \\
\mathbf{P}<0.05 \\
\mathbf{P}<0.05 \\
\text { N.S. }\end{array}$ \\
\hline Total & . & $258(3,126)$ & $254(3,820)$ & $P<0.01$ \\
\hline
\end{tabular}

N.S. = Not significant.

Figures in parentheses are numbers of patients on which each mean is based. (Male patients seen at Institute of Directors Medical Centre, 1964-8.?

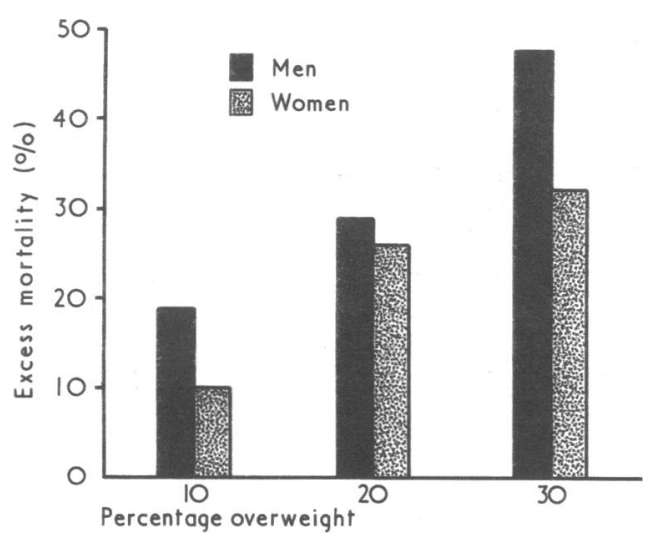

FIG. 1-Excess mortality among overweight subjects. (By permission of the Society of Actuaries. ${ }^{8}$ )

several factors causing obesity, which carries a higher mortality rate (Fig. 1). ${ }^{8}$ Many people have a normal appetite but are too inactive physically to be able to satisfy it without putting on weight, and so they condemn themselves to the misery of semistarvation. The experts agree that a normal diet can be enjoyed if enough exercise is taken.

\section{Exercise and Coronary Heart Disease}

Research has concentrated mainly on the relation between exercise and coronary heart disease. It falls into two broad groups:

\section{“ON-THE-JOB” ACTIVITY}

Most studies have been of this type for the simple reason that it is easy to ask a man his job but difficult to measure his physical activity at other times. One of the earliest and probably the best known investigation of this type was the comparative study by Morris et al..$^{\circ}$ of bus drivers and bus conductors, which started from the observation that conductors (more active) had a lower coronary incidence than drivers (less active). Both here and in other countries there have been numerous studies $^{10}$ along these lines (Fig. 2 ). ${ }^{11}$

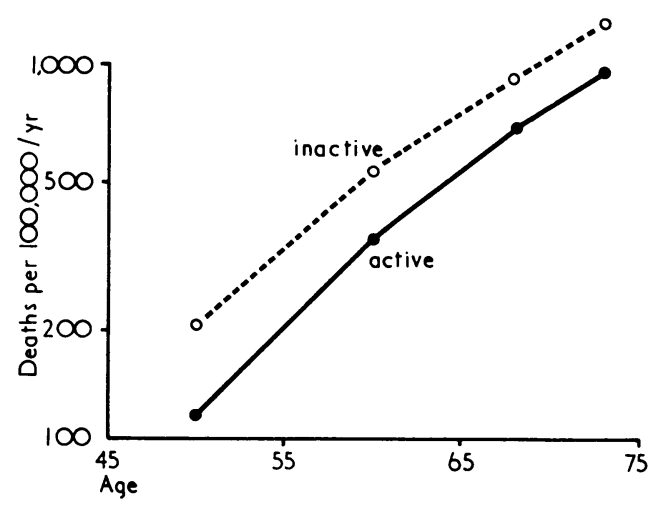

FIG. 2-Age-specific mortality rates from arteriosclerotic heart disease (I.S.C. 420) among inactive (clerical) and certain active occupation groups of men. (Source: Registrar General. ${ }^{11}$ )

The evidence from these occupational studies undoubtedly suggests that coronary thrombosis is both more frequent and more fatal among physically inactive workers. But no study conclusively shows the causal connexion. This failure may be attributed to the greater bugbear of this type of study-namely, the self-selection of the individuals in the contrasted groups plus the effect of other uncontrolled (social, economic, psychological) variables which may cause differences between them.

\section{“OFF-THE-JOB” ACTIVITY}

A man cannot be expected to change his job in order to reduce his risk of heart disease. It is the leisure-time studies, then, which are of the greatest practical moment. Unfortunately there have been fewer of these, though there are now signs of a general shift towards them. Probably the most important inquiries of this type are the two studies which are in progress by Morris and Rose respectively into coronary heart disease as related to the habitual out-of-work physical activities of civil servants. Rose ${ }^{12}$ has already reported his preliminary findings (Fig. 3).

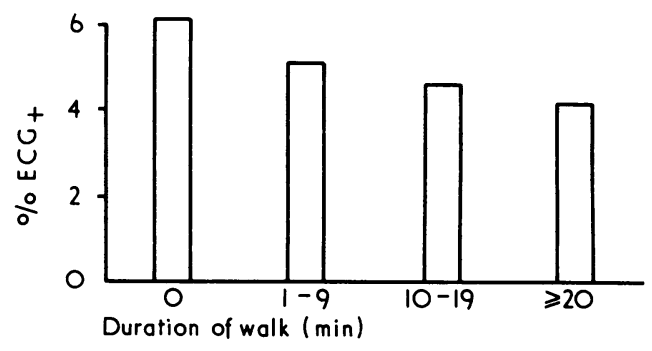

FIG. 3-Relation between ischaemic E.C.G. findings and duration of daily walk to work among 8,948 male civil servants aged 40-64 years (excluding messengers and men with history of dyspnoea and angina). (From study by mose. ${ }^{12}$ )

What conclusions can we draw from all these studies about the relation between coronary disease and activity? Active men appear to have two or three times less risk of coronary thrombosis, and the probability of surviving a first heart attack is two or three times greater. ${ }^{18}$ Though no definite causal connexion between greater activity and prevention of coronary disease has been shown it is important to remember that an unproved proposition is not a false proposition. It is a question of probabilities, and with every fresh study that is completed the odds on exercise having protective value against coronary heart disease are 
shortening. It is perhaps relevant to note that the researchers in this field, however cautious they may be in assessing the evidence and coming to conclusions on the basis of it, are to a man unanimous in favour of the community's taking more exercise. Along with weight reduction and stopping smoking regular physical activity can now reasonably be recommended to those who wish to reduce the likelihood of coronary disease.

\section{How to Acquire Fitness}

For those who want to be fit how should they set about it? Firstly, a word of warning. Except for children it is unwise to embark on a sudden hard exercise without training, and for the middle-aged it can be actually dangerous. The occasional reports of sudden death on a squash court may be attributed to this. In an $80-\mathrm{km}$ cross-country skiing race in Scandinavia in which 10,000 men and women with an average age of 40 took part there were two over the age of 50 who died. One, however, had had a myocardial infarction only three weeks previously, and the other already had severe angina. Clearly they should never have taken part. In this respect training in youth is unimportant; the crucial fact is whether this training has been carried through to later life.

The best advice to the unfit is to take the exercise unobtrusively at first by walking upstairs instead of taking the lift, walking part of the way to work, or walking during the lunch hour. The calorie costs of ordinary activities are shown in Table III. ${ }^{14}$ General practitioners who know their patients' habits can then decide how quickly the exercise programme can be increased without risk. In general it is activities which cause mild breathlessness and increase the heart rate which improve endurance fitness. Isometrics, which were fashionable a few years ago, increase muscular strength without improving the heart or lungs much. It is unnecessary to use complicated testing to gauge whether the exercise is too severe. All that is necessary

TABLE III-Approximate Hourly Calorie Requirements for Various Activities

\begin{tabular}{|c|c|c|c|c|c|c|c|}
\hline Writing & $\ldots$ & $\ldots$ & 20 & Walking & $\ldots$ & $\ldots$ & 350 \\
\hline Sitting & $\therefore$ & $\therefore$ & 15 & Running & $\because$ & $\because$ & $800-1,000$ \\
\hline Standing & $\ldots$ & $\ldots$ & 20 & Gymnastics & $\ldots$ & . & $200-500$ \\
\hline Dress & $\therefore$ & $\therefore$ & $30-40$ & Golf $\quad .$. & $\therefore$ & $\because$ & 300 \\
\hline Tailor & $\because$ & $\because$ & $50-100$ & Soccer & $\therefore$ & $\because$ & 500 \\
\hline House painter & $\therefore$ & $\because$. & 200 & Canoeing & $\ldots$ & $\because$ & 42 \\
\hline Coal-mining & .. & . & 400 & Rowing & .. & .. & 1,200 \\
\hline Sawing wood & $\ldots$ & . & 600 & Swimming & $\therefore$ & $\because$ & $700-90$ \\
\hline Polishi & . & $\therefore$ & $150-200$ & Skating & $\ldots$ & .. & $600-700$ \\
\hline Carpenter & $\because$ & $\because$. & 200 & Tennis & $\because$ & $\ldots$ & $400-500$ \\
\hline
\end{tabular}

From Mayer, ${ }^{14}$ by permission of University of Illinois. is common sense. If running is the chosen activity it should be at a speed at which conversation with a companion can be comfortably maintained. The final balance of different physical activities should be entirely a matter of individual choice. Some may want to do ten minutes of gymnastics each morning, and for them the 5BX Canadian exercises ${ }^{15}$ are useful. The trouble with fitness schemes is that like so many slimming schemes they fizzle out. Some may like to know the equivalent in terms of training effect of a wider range of activities, and for them the Cooper aerobic scheme ${ }^{16}$ is useful. The aim of such schemes is to give a progressive course of training that will turn physical exercise into a "habit."

\section{Implications for Government}

The present situation is that there are now many straws in the wind, all pointing to the conclusion that moderate daily exercise has preventive value against coronary heart disease. As coronary disease is such a major cause of death the potential savings to the nation's health bill are enormous, so that it seems to us that the Department of Health, perhaps in liaison with the M.R.C., should give their full support to this field of research. In "Rothschild" terms they now have a strong "customer interest" in supporting research which would help to clarify these findings. The Sports Council, in collaboration with the M.R.C. and others, are sponsoring a project entitled "Exercise and the Middle-aged Man," which we hope will take us a little way along this road. But much more needs to be done.

It is perhaps worth pointing out that several European governments assume that sport and health are related. For example, as long as 15 years ago West Germany based a "Golden Plan" at least in part on this premise. This plan led to an average annual national expenditure on recreational provision three times as great as in this country, and it has been sustained ever since. Six European countries now have-government-backed fitness campaigns of various kinds. The "Sport for All" theme is now part of a common European philosophy, and though the manner of achieving it may differ in each country each has something to learn from the other.

We are a sports council not a fitness council and have so far taken the view that fitness schemes can be too narrow and arid to have a wide appeal. Although there may be a small number of people who will undertake regular physical activity as a precaution against sickness and disease the vast bulk of the population can only be adequately attracted for any length of

TABLE IV-Motives for Participation in Sport and Recreation

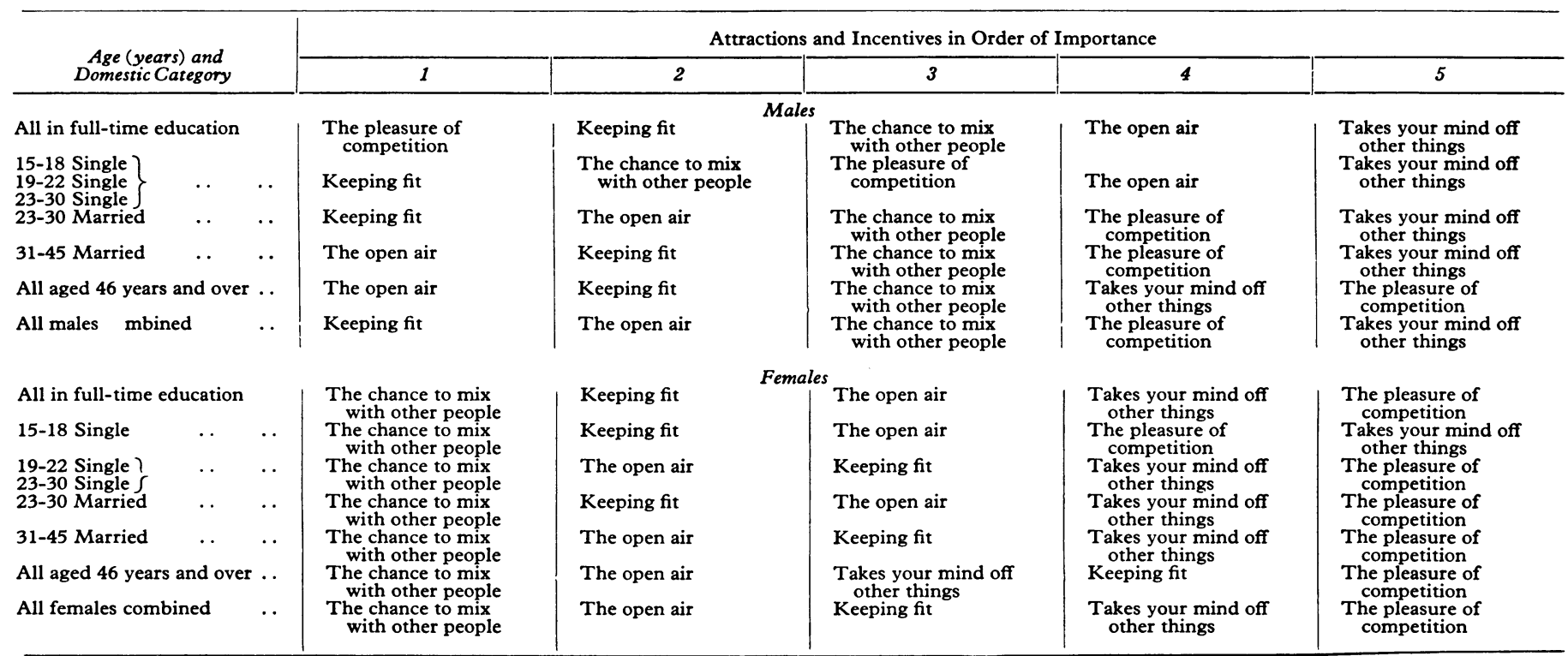


time towards activities which are in themselves rewarding, enjoyable, and satisfying. Our policy chimes in with the way people naturally feel about sport and games ${ }^{317}$ (Table IV).

But people cannot play games and go in for physical recreation unless there is a place where they can do so. Therefore, in pressing for a more realistic and appropriate level of recreational provision (as we do in Provision for Sport ${ }^{18}$ and Sport in the Seventies, ${ }^{19}$ and now in our "Sport for All" campaign) we can claim that we are not only abiding faithfully by our avowed goal but also doing what may in the long run-when an exercise and health relationship is definitely established-prove to be of service to the nation's physical and mental wellbeing. Sport is to be seen not simply as part of a fully rounded life but as an essential part and should not be treated as a residual element when it comes to spending of Government or local authority funds.

What kind of facilities make sense? There are now 50 indoor sports centres built and 100 more in construction. ${ }^{20} 21$ Such sports centres have proved an outstanding success and are clearly major costs in sporting provision of the future. They make sense in a country with uncertain weather and long dark winter evenings. Any properly managed centre is full all day and every evening, used for activities like badminton, squash, handball, gymnastics, judo, dancing, even theatricals, not to speak of restaurant and crèche. The recreational facilities for new schools can be designed for community use too, extra money for capital and running costs coming from the local authority. This makes sound social as well as financial sense. I can foresee a time when sports facilities, squash courts, recreation rooms, and swimming pools will become a mandatory and integral part of every major new building, whether it be hotel, factory, flat, or office block-as usual and necessary as modern plumbing.

As doctors we are in danger of being cast in the bleak role of saying "no" to so many things-eating, smoking, drinking, drugs, and now even to too many babies. Somehow our cumulative advice is deadening, giving people a negative view of health. Instead could we not say a massive "yes" to innocent, wholehearted recreational pursuits, so giving a considered, buoyant, positive view of health ? Over a century ago Sir Edwin Chadwick, whose memory we honour today, fought to improve the water supply, drainage, and cleansing of our great cities. Now that these and so many other health battles have been won can we not join the new planning battle of the next decade for realistic community recreational provision in order to, as Åstrand ${ }^{13}$ said, "add life to years, not just years to life"?

\section{References}

1 Wolfenden-Committee on Sport, Sport and the Community. London Central Council of Physical Recreation, 1960.

${ }^{2}$ Central Statistical Office, The United Kingdom in Figures. London, H.M.S.O., 1972 .

3 Sillitoe, K. K., Planning for Leisure. London, H.M.S.O., 1969.

4 McIntosh, P., Sport in Society. London, Watts, 1963.

Geiringer, E., Bulletin of Physical Education, 1972, p. 19.

6 Bannister, R., Proceedings of the Royal Society of Medicine, 1969, 62, 1159

7 Pincherle, G., Proceedings of the Royal Society of Medicine, 1969, 62, 118

Society of Actuaries, Build and Blood Pressure Study. Chicago, Society of Actuaries, 1959

${ }^{9}$ Morris, J. N., Heady, J. A., Raffel, P. A. B., Roberts, C. G., and Park, J. W., Lancet, 1953, 2, 1053.

10 Larsen, O. A., and Malmborg, R. O., Coronary Heart Disease and Physical Fitness. Copenhagen, Munksgaard, 1971.

11 Registrar General, Decennial Supplement, England $\&$ Wales 1951, Occupational Mortality. London, H.M.S.O., 1954.

12 Rose, G., Proceedings of the Royal Society of Medicine, 1969, 62, 1183.

13 Astrand, P., Health and Fitness. Stockholm, Swedish Information Service and Skandia Insurance, 1971 .

14 Mayer, J., in Exercise and Fitness, University of Illinois, College of Physical Education and Athletic Institute Colloquium. Urbana, University of Illinois, 1959.

15 Royal Canadian Air Force, Physical Fitness. Harmondsworth, Penguin, 1971.

16 Cooper, K. H., New Aerobics. New York, Evans, 1970.

7 Bone, M., assisted by Ross, E., Youth Service and Similar Provision for Young People. London, H.M.S.O., 1972.

18 Department of the Environment, Provision for Sport (Indoor Swimming Pools, Indoor Sport Centres and Golf Courses). London, H.M.S.O. 1972.

19 Sports Council, Sport in the Seventies: The Need for a Planned Programme of Capital Investment. London, H.M.S.O., 1972.

20 Sports Council, Indoor Sports Centres. London, H.M.S.O., 1971

21 Sports Council, Planning for Sport. London, Central Council of Physical Recreation, 1968.

\section{Follow-up of Hydatidiform Mole by Radioimmunoassay of Human Chorionic Gonadotrophin}

\section{J. W. CRAWFORD}

British Medical fournal, 1972, 4, 715-719

\section{Summary}

An improved method for the follow-up of patients delivered of a hydatidiform mole using radioimmunoassay of human chorionic gonadotrophin is employed to ensure adequate sensitivity. Four illustrative case histories are described. Their HCG findings are presented to show that this is the principal basis on which decisions should be made.

There are three aspects to the work of the laboratory. The technical work of the assay, the clerical effort of patient follow-up, and the clinical interpretation of results. The laboratory keeps a close check on follow-up (one of its most important functions) and receives specimens direct from patients.

Department of Obstetrics and Gynaecology, University of Dundee

J. W. CRAWFORD, M.B., M.R.C.o.G., Consultant in Obstetrics and Gynaecology and Honorary Senior Lecturer
Overall control of all three aspects is by a clinician. It has been found useful to organize a special clinic for these patients to be seen. In this region it has been possible for this to be run by the same clinician.

\section{Introduction}

For many years gynaecologists have been taught that patients recently delivered of a hydatidiform mole should be "followed" for a period of two years lest a choriocarcinoma develop undetected. Traditionally follow-up consisted in clinical examination and "pregnancy" testing every three months. It has recently been appreciated that more frequent follow-up is necessary, particularly in the early months after delivery of a hydatidiform mole.

Many attempts have been made to improve follow-up procedures, yet Bagshawe et al. stated recently: "It is apparent from this series that strenous efforts have been made by 